\title{
Prevention of Mother-to-Child Transmission of HIV/AIDS: Perception of Health Care Workers in Rural Areas of Oyo State
}

\author{
Usman Aishat $^{1}$ and Ayinde Olubunmi ${ }^{2}$ \\ ${ }^{1}$ Department of Community Medicine, LAUTECH Teaching Hospital, PMB 5000, Osogbo, Osun State, Nigeria \\ ${ }^{2}$ HIV/AIDS Unit, Oyo State Ministry of Health, Ibadan, Nigeria \\ Correspondence should be addressed to Usman Aishat; labukol@yahoo.com
}

Received 24 June 2015; Accepted 12 November 2015

Academic Editor: Sai-Yin Ho

Copyright (c) 2016 U. Aishat and A. Olubunmi. This is an open access article distributed under the Creative Commons Attribution License, which permits unrestricted use, distribution, and reproduction in any medium, provided the original work is properly cited.

\begin{abstract}
Introduction. Proper implementation of prevention of mother-to-child transmission (PMTCT) services requires adequate knowledge and appropriate attitudes and practices on the part of the health care providers especially in rural areas where access to health care delivery is very limited in Oyo State. Materials and Methods. This is a descriptive cross-sectional survey of 350 health care workers in a two-stage sampling technique. Data was obtained using interviewer-administered, pretested, semistructured questionnaires. The data was analyzed using Epi Info software version 7. Results. The knowledge of PMTCT of HIV was poor among the health care workers (69.1\%). However, more than half (58.3\%) had good attitudes towards PMTCT of HIV/AIDS. Predictors of good knowledge of PMTCT were religion $[\mathrm{AOR}=1.6,95 \% \mathrm{CI}(1.1-2.6)]$, cadre of occupation [AOR = 10.2, 95\% CI (2.9-35.1)], and length of service $[\mathrm{AOR}=4.3,95 \% \mathrm{CI}(2.3-19.4)]$. Predictors of good attitude towards PMTCT were length of service in the current hospital $[\mathrm{AOR}=2.8,95 \% \mathrm{CI}(1.5-5.2)]$ and cadre of occupation [AOR $=3.9,95 \% \mathrm{CI}(1.28-11.9)]$. Conclusion. Despite poor knowledge of PMTCT of HIV/AIDS among the health care workers, the attitude towards PMTCT of HIV/AIDS was good. There is need for the involvement of the stakeholders in bridging the gap between knowledge of and attitude towards prevention of MTCT of HIV/AIDS among health care workers in the rural areas.
\end{abstract}

\section{Introduction}

Globally, about forty million people are currently living with HIV [1]. This is about one percent of the world population. In 2006, there were about 4.3 million new HIV infections worldwide. Of the total number of AIDS patients globally 48 percent is women with 59 percent in sub-Saharan Africa [2].

It is estimated that more than $60 \%$ of Nigerian population lives in rural areas, most of whom are underserved in terms of social amenities [3]. Also, facilities that provide services are concentrated in urban areas particularly in secondary and tertiary health facilities. Universal coverage of highly active ARV treatment (HAART) for HIV-positive pregnant women in Oyo State which is 38\% is far below the target of $80 \%$ [4].

There is a limited comprehensive intervention package available to postpartum mothers in most health facilities in Oyo State. Interventions on PMTCT were offered in some facilities in Oyo State through the AIDS Prevention Initiative in Nigeria (APIN) project funded by President's
Emergency Plan for AIDS Relief (PEPFAR). Child survival is compromised due to limited access to prevention services, in Oyo State.

Prevention of mother-to-child transmission has been considered as not a simple intervention but a comprehensive set of interventions requiring capable health workers. It starts with testing pregnant women for HIV, preferably during their first antenatal visit. When giving the test result, health care workers should provide good counselling, including information about PMTCT options.

The health system should ensure that HIV-positive women receive the PMTCT services that they choose and should provide postnatal care. All along the timeline from finding out their serostatus to getting treatment for HIVrelated problems, women and their children should be followed up closely. The need for comprehensive and longterm care for HIV-infected women has become a challenge for health systems, particularly where lack of coordination among different facilities is common $[5,6]$. 
We assessed perceptions of health care workers in rural areas of PMTCT services in Oyo State. The findings of this study should inform the development of a more effective program for the fourth prong of the WHO-recommended comprehensive PMTCT program.

\section{Methods}

This study was a descriptive cross-sectional survey of health care workers in rural PMTCT clinics in Oyo State, southwestern Nigeria. The study was carried out in October 2013. There are three senatorial districts with 120 PMTCT clinics in Oyo State, of which 50 were in rural areas of the state. Selection of respondents was based on their function, position, and experience in the implementation of PMTCT services. Interviewees were first screened to check that they had appropriate positions and at least one year of experience with PMTCT, so that they could provide insightful information. They included doctors, nurses, midwives, community health extension workers, and health assistants. Three hundred and fifty respondents were recruited to the study using a two-stage sampling technique.

Stage 1: The list of all the PMTCT clinics in the rural areas in each senatorial zone was obtained. Simple random sampling was used to select 10 clinics out of the 50 clinics in the rural areas of the state using proportional allocation. Simple random sampling was used to select 5 clinics from Oyo South senatorial zone, 2 clinics from Oyo Central zone, and 3 clinics from Oyo North senatorial zone.

Stage 2: A list of health workers in each PMTCT clinic that was sampled was obtained. Respondents were selected using systematic sampling: the first respondent was randomly selected and every 5 th person was chosen as the next respondent until the desired sample size per facility was obtained.

Data was collected with pretested, semistructured interviewer-administered questionnaire. The questionnaire obtained information on the sociodemographic data of the respondents and knowledge and attitude towards the prevention of MTCT of HIV/AIDS. Data was entered into a computer and analyzed using the Epi Info software version 7 [7]. Composite knowledge and attitude scores were computed for PMTCT-related knowledge and attitude by scoring 1 for each correct answer and 0 for an incorrect answer. These scores were then summed up and divided by the total number of test items to arrive at an average knowledge and attitude score per person. Association between sociodemographic characteristics and knowledge of PMTCT of HIV/AIDS was examined using the odds ratio with level of significance set at $5 \%$. Ethical approval was obtained from Oyo State Ministry of Health Ethical Review Committee and written informed consent was obtained from all interviewees, who were invited to participate voluntarily. The interviews were conducted privately and anonymously. There were no refusals.

\section{Results}

Three hundred and fifty questionnaires were administered. Table 1 shows the background characteristics of the respondents. Mean age of respondents was $40 \pm 6.8$ years.
TABLE 1: Background characteristics of respondents.

\begin{tabular}{|c|c|}
\hline Characteristics & Frequency (\%) \\
\hline \multicolumn{2}{|l|}{ Length of service (years) } \\
\hline $1-5$ & $38(10.9)$ \\
\hline $6-10$ & $103(29.4)$ \\
\hline $11-15$ & $119(34.0)$ \\
\hline $16-20$ & $55(15.7)$ \\
\hline$\geq 21$ & $35(10.0)$ \\
\hline Mean length of service & $12.66 \pm 6.65$ \\
\hline \multicolumn{2}{|l|}{ Age group } \\
\hline$\leq 29$ & $27(7.7)$ \\
\hline $30-34$ & $26(7.4)$ \\
\hline $35-39$ & $80(22.9)$ \\
\hline $40-44$ & $121(34.6)$ \\
\hline$\geq 45$ & $96(27.4)$ \\
\hline Mean age \pm standard deviation & $40 \pm 6.8$ years \\
\hline \multicolumn{2}{|l|}{ Sex } \\
\hline Male & $61(17.4)$ \\
\hline Female & $289(82.6)$ \\
\hline \multicolumn{2}{|l|}{ Level of education } \\
\hline University & $99(28.3)$ \\
\hline College & $76(21.7)$ \\
\hline Secondary & $35(10.0)$ \\
\hline Primary & $140(40.0)$ \\
\hline \multicolumn{2}{|l|}{ Cadre of workers } \\
\hline Doctor & $16(4.6)$ \\
\hline Nurse & $73(20.9)$ \\
\hline $\mathrm{CHO}$ & $30(8.6)$ \\
\hline CHEW & $33(9.4)$ \\
\hline Health assistant & $198(56.6)$ \\
\hline \multicolumn{2}{|l|}{ Religion } \\
\hline Christianity & $227(64.9)$ \\
\hline Islam & $123(35.1)$ \\
\hline \multicolumn{2}{|l|}{ Marital status } \\
\hline Married & $328(93.7)$ \\
\hline Widowed & $10(2.9)$ \\
\hline Single & $12(3.4)$ \\
\hline
\end{tabular}

Table 2 shows knowledge of health care workers in Oyo State of PMTCT. Overall $37.5 \%$ had good knowledge of PMTCT of HIV/AIDS.

Table 3 shows attitude of respondents towards PMTCT. The majority of the respondents (89.7\%) agreed that PMTCT is an important program. Almost all the respondents (91.4\%) agreed that there was not enough time to render PMTCT services.

Table 4 shows the association between background characteristics of respondents and knowledge level of PMTCT of HIV/AIDS. The bivariate and multivariate analysis show that marital status, sex, and time spent in the current hospital had no significant association with PMTCT knowledge. Health care workers who were Christian were two times more likely to be knowledgeable about PMTCT than the Muslims $[\mathrm{AOR}=1.6,95 \% \mathrm{CI}(1.3-7.8)]$. Doctors and nurses were 
TABLE 2: Respondents knowledge of PMTCT of HIV/AIDS $(n=350)$.

\begin{tabular}{lcc}
\hline Variables & Correct response (\%) & Wrong response (\%) \\
\hline HIV Prevalence in general population & $170(48.6)$ & $180(51.4)$ \\
HIV Prevalence in women & $144(41.1)$ & $206(58.9)$ \\
Full meaning of acronyms of PMTCT & $153(43.7)$ & $197(56.3)$ \\
Vertical transmission risk & $226(64.6)$ & $124(35.4)$ \\
Transmission risk with breastfeeding & $256(73.1)$ & $94(26.9)$ \\
Awareness of guidelines on PMTCT & $100(28.6)$ & $250(71.4)$ \\
When to initiate PMTCT drugs & $123(35.1)$ & $227(68.9)$ \\
\hline
\end{tabular}

TABLE 3: Attitude of health care workers towards PMTCT of HIV/AIDS $(n=350)$.

\begin{tabular}{|c|c|c|c|}
\hline \multirow{2}{*}{ Variables } & \multicolumn{3}{|c|}{ Number (percentage) } \\
\hline & Disagree & Indifferent & Agree \\
\hline PMTCT program is very important & $24(6.9)$ & $29(8.3)$ & $297(84.9)$ \\
\hline Providing PMTCT stops us from providing good ANC care & $257(73.4)$ & $29(8.3)$ & $64(18.5)$ \\
\hline I am scared to deliver HIV-positive women because of fear of infection & $157(44.9)$ & $12(3.4)$ & $181(51.7)$ \\
\hline HIV-infected pregnant women must be delivered by skilled personnel & $44(12.6)$ & $72(20.6)$ & $234(66.9)$ \\
\hline There is not enough time to give to PMTCT services & $18(5.1)$ & $12(3.4)$ & $320(91.4)$ \\
\hline HIV-infected woman may not breastfeed her child if there is risk of infection & $97(27.7)$ & $64(18.3)$ & $189(54.0)$ \\
\hline
\end{tabular}

ten times more likely to be knowledgeable about PMTCT of HIV/AIDS than health assistants $[\mathrm{AOR}=10.2,95 \% \mathrm{CI}$ (3.0-35.1)]. Health care workers who had spent 5 years and more in the hospital were four times more likely to be knowledgeable about PMTCT of HIV/AIDS than those who had spent less than 5 years.

Table 5 shows association between background characteristics of respondents and their attitude towards PMTCT. Health care workers who had spent between 5 years and above were three times more likely to have good attitude towards PMTCT of HIV/AIDS than those who had spent less than 5 years in the current hospital [AOR $=2.7,95 \%$ CI (1.5-5.2)]. Community health officers/community health extension officers were four times more likely to have good attitude towards PMTCT of HIV/AIDS than health assistants $[\mathrm{AOR}=3.9,95 \% \mathrm{CI}(1.3-11.9)]$.

\section{Discussions}

Health care workers had poor knowledge about PMTCT of HIV/AIDS. Though the knowledge about PMTCT was poor among the respondents, the majority have a good attitude towards PMTCT. This is in contrast to a study done in Botswana, where having a high PMTCT knowledge score was a major factor associated with good attitude towards PMTCT. Also a study carried out in Port Harcourt, Nigeria, reported that $89.3 \%$ of general medical practitioners agreed that their knowledge of, attitude towards, and practice of PMTCT of HIV/AIDS were deficient [8]. In a study conducted on 53 health care workers in Vietnam identified inadequate knowledge and skills regarding PMTCT among health care workers were one of the factors affecting the delivery of PMTCT services [9].

Religion is associated with good knowledge of prevention of MTCT of HIV/AIDS. Being Christian has significant association with good knowledge about PMTCT. This finding is also in line with a study from Osogbo, Nigeria, where religion was associated with knowledge of PMTCT of HIV/AIDS [10]. Also a study from Ghana revealed that Christians had good knowledge of PMTCT compared to the Muslims [11]. This finding may be due to the fact that religious leaders are getting involved in campaigns against HIV infection. Studies have showed that religious organizations are recognized for playing an important role in preventing new infections in Uganda $[12,13]$. Nearly all of its major religious institutions, both Islamic and Christian, have been actively engaged in the country's struggle with HIV/AIDS [12]. Many nongovernmental organizations do plenty of collaborative work with religious organizations in Nigeria, all in a bid to increase awareness of MTCT and its prevention. Unfortunately however, many faith-based organizations see immoral behavior as being the cause of the HIV/AIDS epidemic and they therefore decline involvement in preventive and intervention programs [12].

Doctors and nurses were found to have good knowledge of PMTCT of HIV/AIDS. This is in line with findings of Nneka et al. (2007) where they reported doctors and nurses were more knowledgeable than paramedics [14]. A study from Vietnam revealed that oftentimes training was provided to doctors on HIV/AIDS and PMTCT [9]. This finding may be due to the training doctors and nurses underwent which gives background information on HIV/AIDS better than other cadres of health care workers. It may also be as a result of previous contact and management of HIV-positive pregnant women by doctor and nurses.

Length of services was also associated with good knowledge and attitude towards PMTCT of HIV/AIDS. It was found that health care workers who had spent five years and above were more knowledgeable about prevention of MTCT. This may be due to repetitive exposure to HIV patients 
TABLE 4: Association between background characteristics of respondents and good knowledge of PMTCT of HIV/AIDS.

\begin{tabular}{|c|c|c|c|}
\hline Characteristics & Crude odds ratio & Adjusted odds ratio & $p$ value \\
\hline \multicolumn{4}{|l|}{ Age (years) } \\
\hline$<40$ & $5.7(0.4-5.3)$ & $2.3(0.3-14.0)$ & 0.30 \\
\hline$\geq 40$ & Ref. & & \\
\hline \multicolumn{4}{|l|}{ Sex } \\
\hline Male & Ref. & Ref. & \\
\hline Female & $3.1(1.6-7.5)$ & $1.6(0.9-7.9)$ & 0.12 \\
\hline \multicolumn{4}{|l|}{ Level of education } \\
\hline Less than secondary & $6.3(0.7-11.9)$ & $4.3(0.7-7.5)$ & 0.67 \\
\hline Secondary and above & Ref. & Ref. & \\
\hline \multicolumn{4}{|l|}{ Marital status } \\
\hline Single & Ref. & Ref. & \\
\hline Married & $3.9(0.8-4.6)$ & $2.9(0.4-4.0)$ & 0.27 \\
\hline \multicolumn{4}{|l|}{ Religion } \\
\hline Christianity & $2.1(1.1-4.8)^{*}$ & $1.6(1.3-7.8)$ & $0.01^{*}$ \\
\hline Islam (ref.) & Ref. & & \\
\hline \multicolumn{4}{|l|}{ Cadre of occupation } \\
\hline Doctor/nurse & $10.8(2.7-43.6)$ & $10.2(3.0-35.1)^{*}$ & $0.00^{*}$ \\
\hline $\mathrm{CHO} / \mathrm{CHEW}$ & $0.4(0.3-2.5)$ & $0.9(0.2-4.1)$ & \\
\hline Health assistant & Ref. & Ref. & \\
\hline \multicolumn{4}{|c|}{ Time spent in current hospital } \\
\hline$<5$ years & Ref. & Ref. & \\
\hline$\geq 5$ years & $0.9(0.3-2.9)$ & $4.3(2.3-19.4)^{*}$ & $0.00^{*}$ \\
\hline
\end{tabular}

TABLE 5: Association between background characteristics of respondents and good attitude towards PMTCT of HIV/AIDS.

\begin{tabular}{|c|c|c|c|}
\hline Characteristics & Crude odds ratio & Adjusted odds ratio & $p$ value \\
\hline \multicolumn{4}{|l|}{ Age (years) } \\
\hline$<40$ & $0.7(0.4-1.3)$ & $1.0(0.6-1.8)$ & 0.24 \\
\hline$\geq 40$ & Ref. & Ref. & \\
\hline \multicolumn{4}{|l|}{ Sex } \\
\hline Male & Ref. & Ref. & \\
\hline Female & $2.3(0.9-9.2)$ & $1.9(0.8-6.5)$ & 0.62 \\
\hline \multicolumn{4}{|l|}{ Level of education } \\
\hline Less than secondary & $3.2(0.7-3.9)$ & $2.9(0.9-6.3)$ & 0.12 \\
\hline Secondary and above & Ref. & Ref. & \\
\hline \multicolumn{4}{|l|}{ Marital status } \\
\hline Single & Ref. & Ref. & \\
\hline Married & $1.8(0.2-9.1)$ & $3.8(0.9-4.6)$ & 0.23 \\
\hline \multicolumn{4}{|l|}{ Length of service (years) } \\
\hline$<5$ years & Ref. & Ref. & \\
\hline$\geq 5$ years & $3.2(1.5-6.5)^{*}$ & $2.7(1.5-5.2)^{*}$ & $0.02^{*}$ \\
\hline \multicolumn{4}{|l|}{ Religion } \\
\hline Christianity & $1.5(0.4-3.2)$ & $2.4(0.3-3.8)$ & 0.25 \\
\hline Islam & Ref. & Ref. & \\
\hline \multicolumn{4}{|l|}{ Cadre of occupation } \\
\hline Doctor/nurse & $3.7(0.9-5.6)$ & $0.5(0.1-2.4)$ & $0.01^{*}$ \\
\hline $\mathrm{CHO} / \mathrm{CHEW}$ & $1.4(0.8-9.7)$ & $3.9(1.3-11.9)^{*}$ & \\
\hline Health assistant & Ref. & Ref. & \\
\hline
\end{tabular}


by health care workers thereby acquiring more knowledge through on-job training. There is possibility that HIV training can significantly improve such knowledge regarding HIV transmission and prevention. However, training alone may not have provided adequate information in these areas, since knowledge scores for some items were low for all workers. These results suggest that all health care workers may benefit from increased HIV/AIDS education in the context of PMTCT that recognizes existing gaps and prevent infection.

Therefore, thorough training of health personnel in all aspects of mother-to-child transmission, feeding recommendations and options, and further preventive measures is indispensable.

The finding from this present study revealed that community health officers/extension workers had good attitude towards prevention of mother-to-child transmission of HIV/AIDS. A study from Maiduguri, Nigeria, revealed that nurses had poorer attitude towards PMTCT than doctors and other paramedical staff [14]. This could be due to the fact that the majority of the health care workers in the rural areas were community health officers/extension workers and were already used to delivering PMTCT services. Studies have shown that less specialized cadres of health care workers are capable of effective delivery of HIV care with comparable and even better outcomes as physicians [15]. Length of services was also associated with good attitude towards PMTCT of HIV/AIDS. This may be as a result of on-job training and practice.

\section{Conclusion and Recommendations}

Knowledge and attitudes on PMTCT amongst health care workers show that there was poor knowledge although the attitude was acceptable. Without further training and increase in staffing levels, the quality and access to PMTCT services will likely be negatively impacted. A wide gap exists between the knowledge of and attitude towards PMTCT of HIV/AIDS.

Health promotional activities and behavioral change through effective communication routes such as refreshers course, trainings, and workshops should be promoted. This would take targeted health education messages beyond impacting knowledge. More elaborate studies should be carried out in this field in other parts of Nigeria in order to ensure improvement in knowledge and behavior.

\section{Conflict of Interests}

The authors declare that there is no conflict of interests regarding the publication of this paper.

\section{References}

[1] UNAIDS, "Global Facts and Figures," 2006, http://www.unaids .org/.
[2] UNAIDS, Fact Sheet on Sub Saharan Africa, UNAIDS, 2013, http://www.unaids.org/.

[3] N. Awofeso, "Improving health workforce recruitment and retention in rural and remote regions of Nigeria," Rural and Remote Health, vol. 10, article 1319, 2010.

[4] Ministry of Health, 2010. DHMIS Data Quarter 3, HIV/AIDS Unit, Oyo State, Nigeria, 2012.

[5] J. R. Feussner and J. G. Demakis, "Does health systems thinking guide health services actions?" Health Services Research, vol. 34, no. 7, pp. 1409-1412, 2000.

[6] World Health Organization, "Prevention of mother-to-child transmission (PMTCT)," Briefing Note, Department of HIV/AIDS, Geneva, Switzerland, 2007.

[7] Center for Disease Control, EPI-Info Software Version 7, CDC, Atlanta, Ga, USA, 7th edition, 2012.

[8] O. Okike, I. Jeremiah, and C. Akani, "Knowledge, attitude and practice of general medical practioners in port Harcourt towards prevention of mother to child transmission of HIV," The Nigeria Health Journal, vol. 3, pp. 79-82, 2011.

[9] T. A. Nguyen, P. Oosterhoff, Y. N. Pham, A. Hardon, and P. Wright, "Health workers' views on quality of prevention of mother-to-child transmission and postnatal care for HIVinfected women and their children," Human Resources for Health, vol. 7, article 39, 2009.

[10] A. I. Olugbenga-Bello, W. O. Adebimpe, F. F. Osundina, and S. T. Abdulsalam, "Perception on prevention of mother-to-childtransmission (PMTCT) of HIV among women of reproductive age group in Osogbo, Southwestern Nigeria," International Journal of Women's Health, vol. 5, no. 1, pp. 399-405, 2013.

[11] D. Boateng, G. D. Kwapong, and P. Agyei-Baffour, "Knowledge, Perception about antiretroviral therapy (ART) and prevention of mother-to-child-transmission (PMTCT) and adherence to ART among HIV positive women in the Ashanti Region, Ghana: a cross-sectional study," BMC Women's Health, vol. 13, article 2, 2013

[12] K. Marshall and L. Keough, "Uganda: conquering slimUganda's war on HIV AIDS," in Mind, Heart and Soul in the Fight against Poverty, K. Marshall and L. Keough, Eds., p. 37, World Bank, Washington, DC, USA, 2004.

[13] E. C. Green, Faith-Based Organizations: Contribution to HIV Prevention, The Synergy Project, Washington, DC, USA, 2003.

[14] L. M. Nneka and N. Donna, "KAP of healthcare providers towards prenatal HIV screening and prevention of mother to child transmission of HIV in Nigeria," in Proceedings of the Annual Conference of Global Health Education Consortium, 2007, http://globalhealthec.org/.

[15] C. M. Chama, J. Y. Yahaya, and B. B. Ajayi, "The knowledge, attitude and practice of health workers in Maiduguri with regards to HIV/AIDS and the prevention of mother to child transmission of HIV," Kanem Journal of Medical Sciences, vol. 1, no. 1, pp. 5-9, 2007. 


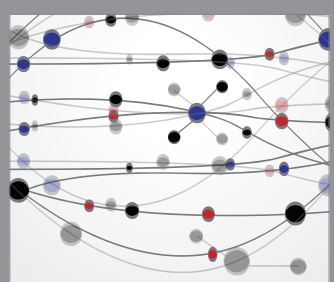

The Scientific World Journal
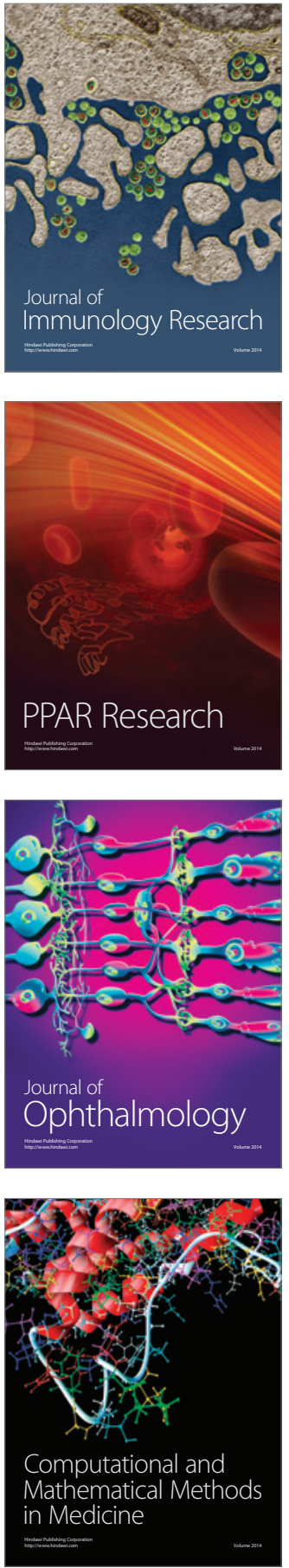

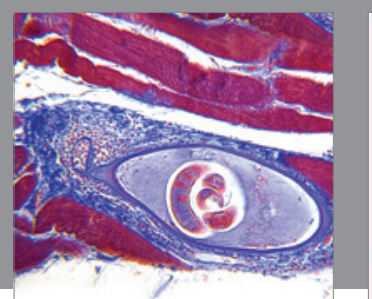

Gastroenterology Research and Practice

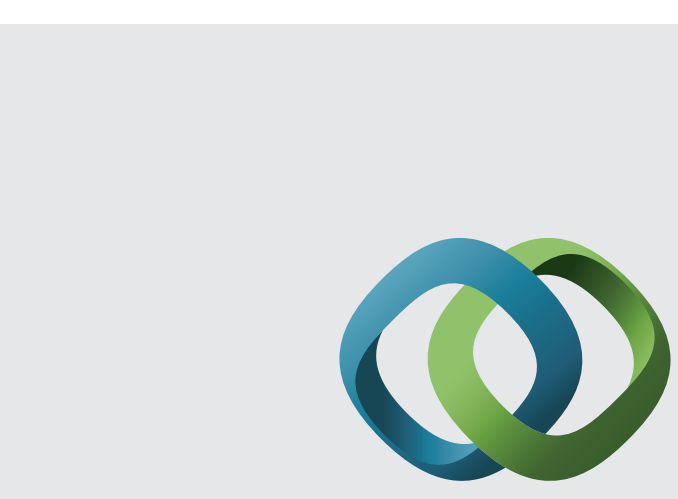

\section{Hindawi}

Submit your manuscripts at

http://www.hindawi.com
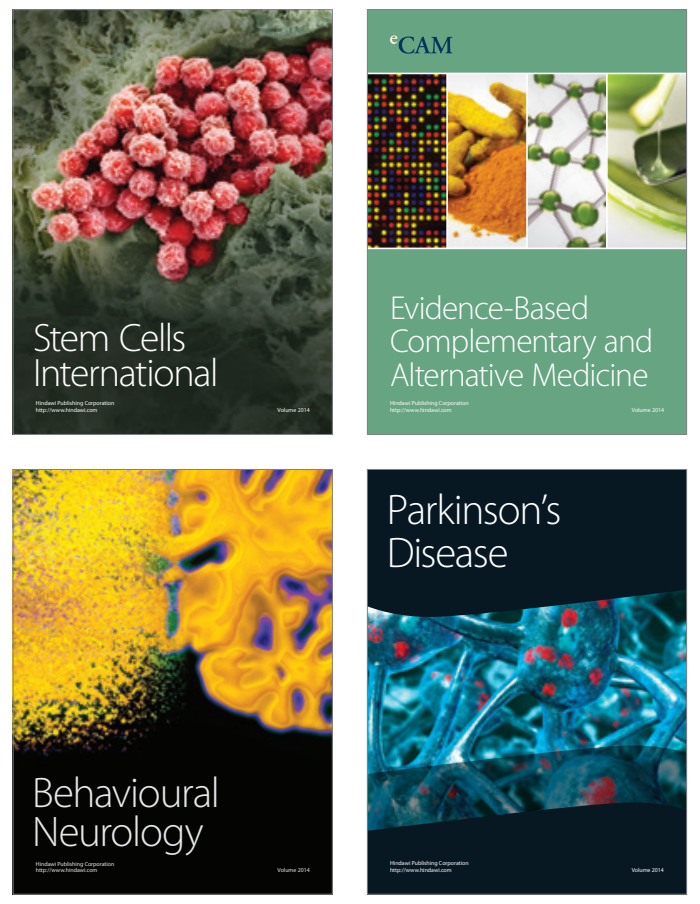
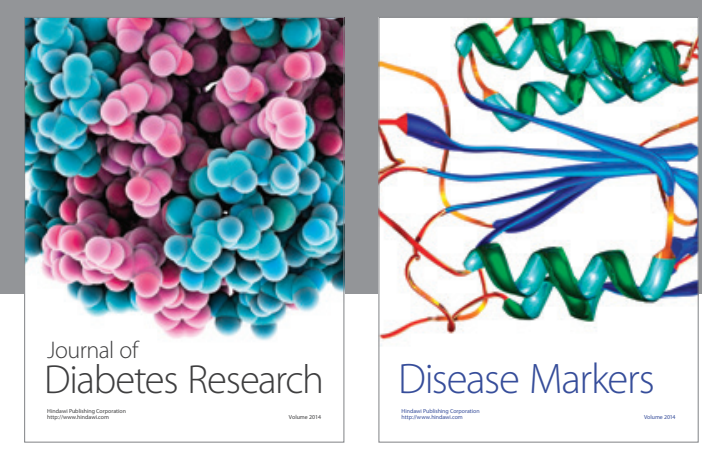

Disease Markers
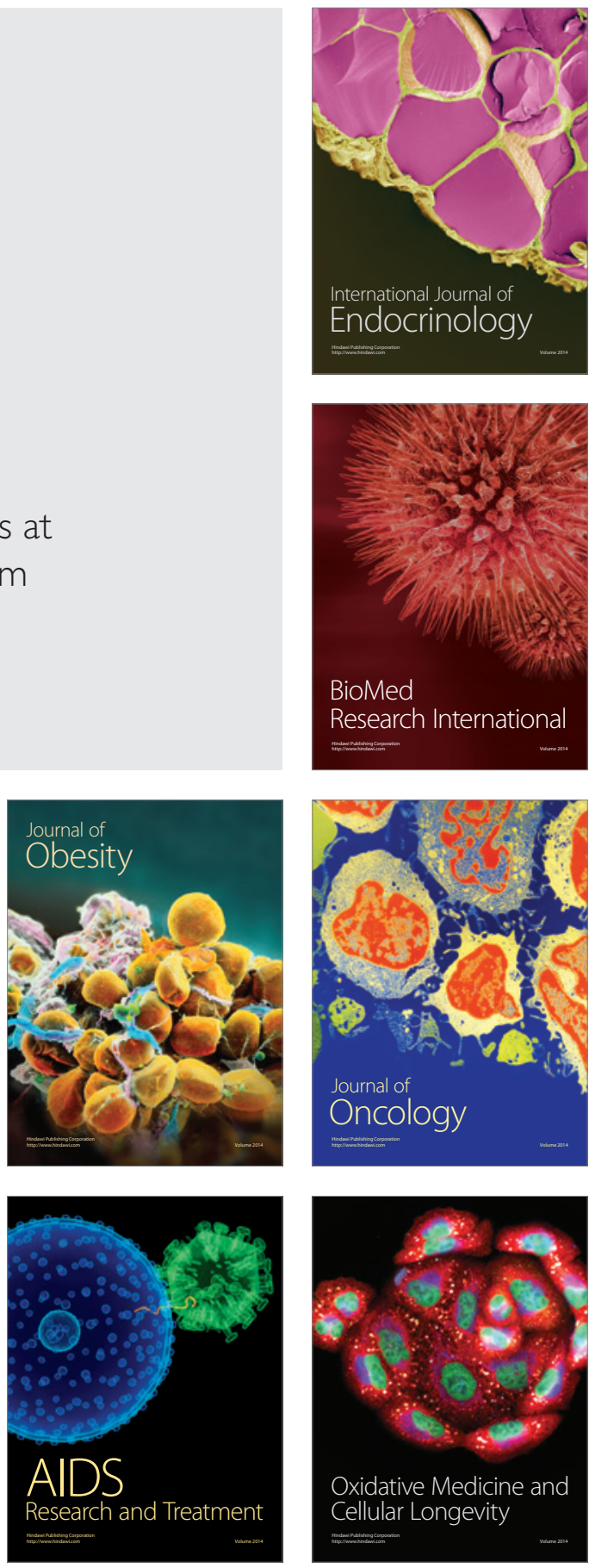